\title{
STUDY OF PP/CLOISITE MMT NANOCOMPOSITE PROPERTIES
}

\author{
Ing. Branislav Duleba, PhD. ${ }^{1}$, Prof. Ing. Emil Spišák, CSc. ${ }^{1}$ \\ ${ }^{1}$ Technical University of Kosice, Faculty of Mechanical Engineering, Department of Technologies \\ and Materials, Mäsiarska 74, Košice, Slovakia, Branislav.duleba@tuke.sk
}

Keywords: polymer nanocomposites, montmorillonite, polypropylene composites, PP, MMT

\begin{abstract}
This paper deals with the explanation of the preparation process for polymer nanocomposites. As a reference matrix, Mosten PND 33-301was used, filled with montmorillonitebased nanofillers (Cloisite 20A, Cloisite 3010). A twin-screw extruder and an injection molding machine were used for the preparation of material and samples, and the relevant parameters are described in the first part of the article. Changes in the basic properties of these PNCs were tested and described in the experimental part of this article. The structures of the materials were observed by SEM microscopy.
\end{abstract}

\section{INTRODUCTION}

It has been more than 50 years since physicist Richard Feynman delivered his lecture titled "There is plenty of room at the bottom" to the American Physical Society. Such a lecture is a landmark in the development of nanotechnology, as Feymann proposed the use of nanotechnology to store information as well as a series of new techniques to support this technology. From then on, the technological and scientific mastery of the nanometric scale has continually become stronger due to new research tools and theoretical and experimental developments. In this scenario, the worldwide nanotechnology market, in the next five years, is expected to be on the order of one trillion dollars. [1]

Nevertheless, only in the late 1980s was the great landmark in the development of polymer clay nanocomposites published by Toyota regarding the preparation and characterization of PA6/organophilic clay nanocomposite to be used in timing belts in cars [2-4]. This new material, with only 4.2 weight percent, showed an increase of $40 \%$ in the rupture tension, $68 \%$ in Young's modulus and $126 \%$ in the flexural modulus, as well as an increase in the heat distortion temperature from $65^{\circ} \mathrm{C}$ to $152^{\circ} \mathrm{C}$ in comparison with the pure polymer [5]. Since then, several companies have introduced thermoplastic nanocomposites, such as polyamide and polypropylene, in automotive applications [6].

\section{POLYMER NANOCOMPOSITES}

A polymer composite is made by the combination of a polymer and synthetic or natural inorganic filler. Fillers are employed to improve the desired properties of the polymer or simply to reduce costs. Nowadays, the application of polymer composites as engineering materials has become state-of-the-art. Polymer composites with improved mechanical, thermal, barrier and fire retardancy properties are widely used in very large quantities in a variety of applications. Application of conventional fillers such as talc, calcium carbonate, fibers, etc., often requires the use of a large amount of filler in the polymer matrix to produce any significant improvements in 
the composite properties, and which may result in some other undesired properties such as brittleness or loss of opacity. [7]

A polymer nanocomposite is defined as a composite material in which at least one dimension of at least one component is on the nanometer size scale $(<100 \mathrm{~nm})$. In recent years the characterization and control of structures on the nanoscale has been studied, investigated and exploited by learning from our natural surroundings. Consequently, nanocomposite technology has emerged as an efficient and powerful strategy for upgrading the structural and functional properties of synthetic polymers. This is the new nanocomposite science, that was started by the Toyota report [8] on the superior improvements in the properties of nylon-6by preparation of exfoliated nylon-6/clay nanocomposites and has been continued by more recent studies on the use in polymeric composites of carbon nanotubes, carbon nanofillers, exfoliated graphite, nanocrystaline metals and fibers modified with inorganic fillers. [9]

\section{EXPERIMENTAL PART}

The aim of this paper is to present the possibilities for manufacturing PP/MMT nanocomposites and describe the changes in the properties of polypropylene Mosten PND 33-301. For this experiment, montmorillonite nanofillers were chosen:

- Cloisite 20A - Montmorillonite modified with a quaternary ammonium salt. It improves various physical properties of plastics, such as reinforcement, HDT, CLTE and barrier properties, modified by hydrogenated tallow (2M2HT $65 \% \mathrm{C} 18 ; \sim 30 \% \mathrm{C} 16 ; \sim 5 \% \mathrm{C} 14$ ), Anion: Chloride,

- Cloisite 3010 - is bentonite treated with a surfactant (supplied by Sud-Chemie); the surface modifier used is dimethyl benzyl hydrogenated tallow alkyl ammonium.

\subsection{Preparation of polymer nanocomposite}

A concentrate containing $10 \%$ nanofiller in the PP polymer matrix was prepared at the Institute of Engineering Polymeric Materials and Colors in Torun, Poland (Instytut Inżynierii Materiałów Polimerowych i Barwników, Toruń). The processing of materials was performed in a Buhler twin-screw extruder BTSK 20/40D, shown in Figure 1. The technical parameters of the extruder are given in Table 1.The final processing characteristics are shown in Table 2.
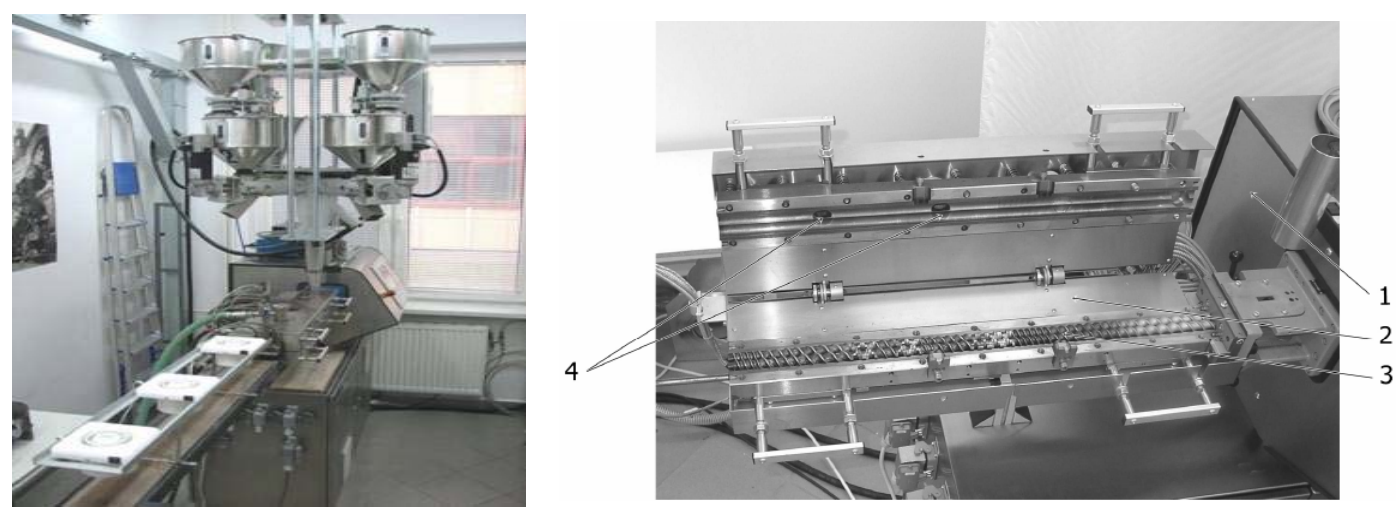

Figure 1: Buhler BTSK 20/40D twin-screw extruder, 1- drive, 2- longitudinal valve, 3- segmental screws, 4- vent points 
Table 1: Buhler BTSK 20/40D twin-screw extruder parameters

\begin{tabular}{|l|l|l|l|}
\hline Screw diameter & $20 \mathrm{~mm}$ & Max. power & $4 \mathrm{~kW}$ \\
\hline Channel depth & $3,75 \mathrm{~mm}$ & Max. speed & $600 \mathrm{rpm}$ \\
\hline Length of cylinder & $800 \mathrm{~mm}$ & Maximum column temperature & $350^{\circ} \mathrm{C}$ \\
\hline Length L & $40 \mathrm{D}$ & Type of cylinder wall cooling & water \\
\hline
\end{tabular}

Table 2: Final processing parameters of PP/MMT preparation process

\begin{tabular}{|l|l|}
\hline Screw configuration & $\mathrm{K} 3$ \\
\hline Torque & $32 \mathrm{Nn}$ \\
\hline Input power & $0,47 \mathrm{~kW}$ \\
\hline Melt temperature in the extruder head & $275^{\circ} \mathrm{C}$ \\
\hline Melt pressure in the extruder head & $4 \mathrm{bar}$ \\
\hline Screw speed & $250 \mathrm{rpm}$ \\
\hline Granulate cooling method & air \\
\hline Temperature ranges & $270-280-280-270-260^{\circ} \mathrm{C}$ \\
\hline Performance of feeder & $10 \mathrm{~kg} / \mathrm{hour}$ \\
\hline
\end{tabular}

Samples for tensile tests were molded by an ARBURG Allrounder 370S injection molding machine in an experimental mold manufactured at KTaM, TUKE under ISO standards. Each material was blended at the three-volume concentrations of $2 \%, 4 \%$ and $6 \%$ of nanofiller and then pre-dried in a vacuum oven according to the technological conditions.

\subsection{Methodology of experiments}

The mechanical properties of the prepared samples were tested on a TiraTest 2300 tensile test machine under the STN ISO 527-1 standard. Before all tests, samples were before conditioned according to the EN ISO 291 standard. The impact strength of the material was tested using a Charpy impact hammer under the EN ISO 179-1 standard. TGA and DSC analyses were performed on a TA Instruments Q600 SDT under EN ISO 11358.

Table 3:Labeling of used materials for tests

\begin{tabular}{|l|l|l|l|}
\hline Material & Label & Material & Label \\
\hline Mosten PND 33-301 & $\mathrm{PP}$ & $\mathrm{PP}+2 \%$ CLOISITE SE 3010 & $\mathrm{B} 2$ \\
\hline $\mathrm{PP}+2 \%$ CLOISITE 20A & $\mathrm{A} 2$ & $\mathrm{PP}+4 \%$ CLOISITE SE 3010 & $\mathrm{B} 4$ \\
\hline $\mathrm{PP}+4 \%$ CLOISITE 20A & $\mathrm{A} 4$ & $\mathrm{PP}+6 \%$ CLOISITE SE 3010 & $\mathrm{B} 6$ \\
\hline $\mathrm{PP}+6 \%$ CLOISITE 20A & $\mathrm{A} 6$ & & \\
\hline
\end{tabular}

\subsection{Assessment of the properties of polypropylene / clay nanocomposites}

Based on the measured values, we can conclude that the addition of nanofiller Cloisite 20A or Cloisite SE 3010 into the polymer matrix had no positive effect on tensile strength and elongation of the material. The addition of $6 \%$ of Cloisite $20 \mathrm{~A}$ caused a decrease in tensile strength of $17.1 \%$. Also, adding a small amount of filler Cloisite $20 \mathrm{~A}$ at a rate of $2 \%$ caused a 
reduction in the yield strength of the material by $4.7 \%$. Material with $6 \%$ of organically modified Cloisite SE 3010 showed a decrease in tensile strength of 23.7\%, as seen in Figure 2.

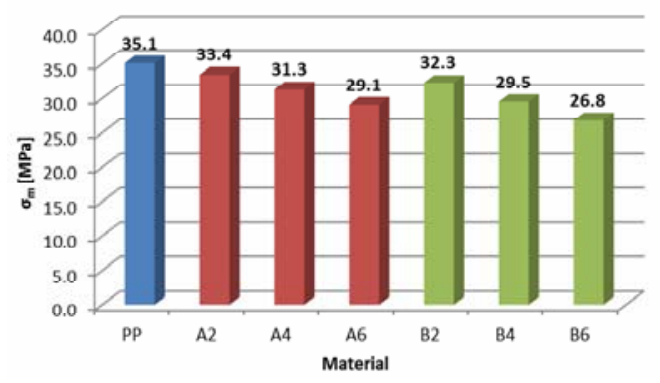

Figure 2: Tensile strength of materials $P P / A$ and $P P / B$

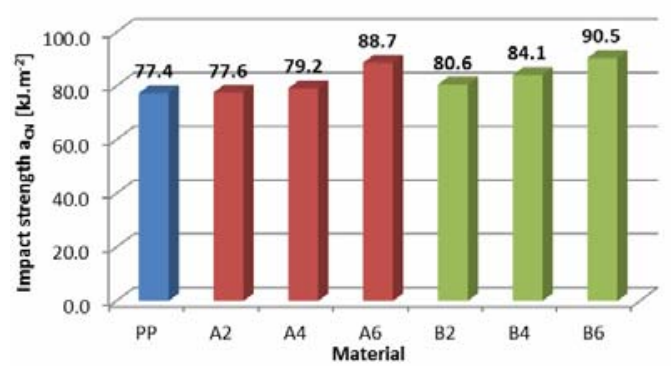

Figure 3: Impact strength of materials $P P / A$ and $P P / B$

Study of the influence of the addition of the Cloisite fillers on the resulting impact strength obtained positive results. Addition of nanofiller Cloisite $20 \mathrm{~A}$ at rate of $6 \%$ achieved an

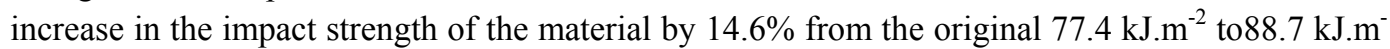
${ }^{2}$. The material containing 6\% filler Cloisite SE 3010 showed an increase in impact strength of $16.9 \%$. Then the hardness of the samples was measured using a Mitutoyo HARDMATIC Type D according to ISO standard 868 and values are illustrated on Figure 4. From the measurements it is clear that the addition of nanofillers in the base material did not have a significant effect on the hardness of the material.

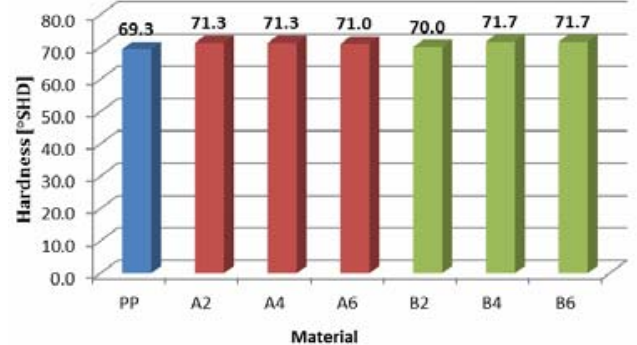

Figure 4: Measured hardness of tested materials

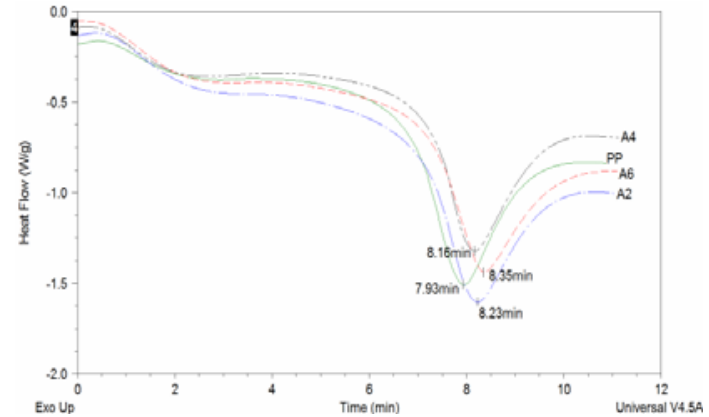

Figure 5: DSC analysis of PP/Cloisite 20A material

The DSC analysis in Figure 5 shows that heating the tested materials to the melting temperature, Tm, shows deviations from the results for the non-composite material. Temperature Tm for virgin polypropylene was achieved in a heating time of $7.93 \mathrm{~min}$, while for the PP/6\% Cloisite 20A this temperature was achieved after $8.35 \mathrm{~min}$, which implies an increase in resistance to elevated temperatures and also the possibility of exposure of the material to higher temperatures for longer times without melting. 
SCIENTIFIC PROCEEDINGS 2013, FacultyofMechanicalEngineering, STU in Bratislava

Vol. 21, 2013, pp. 85-90, DOI: 10.2478/stu-2013-0014

Table 4:DSC/TGA analysis of material PP/Cloisite20A

\begin{tabular}{|l|l|l|l|}
\hline Material & Weight reduction & Temperature $\mathbf{T}_{\mathbf{m}}$ & Heat flow \\
\hline PP & $+0,1539 \%$ & $176,87^{\circ} \mathrm{C}$ & $75,52 \mathrm{~J} / \mathrm{g}$ \\
\hline A2 & $-0,1582 \%$ & $177,51^{\circ} \mathrm{C}$ & $75,52 \mathrm{~J} / \mathrm{g}$ \\
\hline A4 & $-0,08317 \%$ & $176,48^{\circ} \mathrm{C}$ & $75,06 \mathrm{~J} / \mathrm{g}$ \\
\hline A6 & $-0,09538 \%$ & $180,05^{\circ} \mathrm{C}$ & $76,99 \mathrm{~J} / \mathrm{g}$ \\
\hline
\end{tabular}

To better study the structures of the prepared materials, SEM microscope was used. SEM images of material A6 (Figure 6 and Figure 8) show that the exfoliation of the filler was not performed sufficiently. There are visible clumps of filler, undigested filler and also visible air bubbles in the material, on average $1-2 \mu \mathrm{m}$ diameter. These bubbles may result from the treatment of the material, or as residual traces of moisture in the material. In the case of clusters of already fragmented filler, the probable cause is the inappropriateness of the compatibilizer, quaternary ammonium salt. For further investigation, the matrix/filler will be supplied with a compatibilizer to increase the hydrophilicity of polypropylene. The images in Figure 7 and Figure 9 show the structure of PP / Cloisite SE 3010, where clumps of filler are clearly visible in the matrix. The clumps of filler are uniformly dispersed within the base matrix. Pictured are clearly visible clumps of filler and also turgidity after clumping.

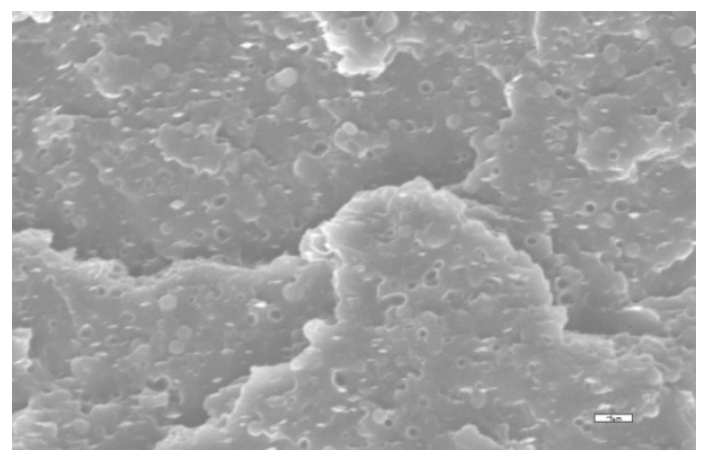

Figure 6: Material PP/A6

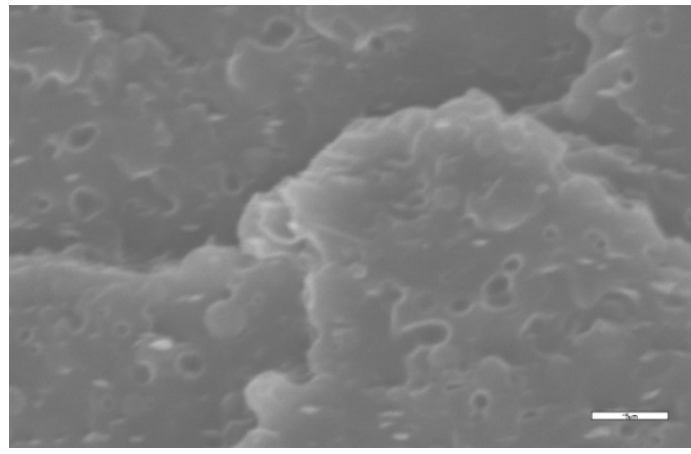

Figure 8: Material PP/A6

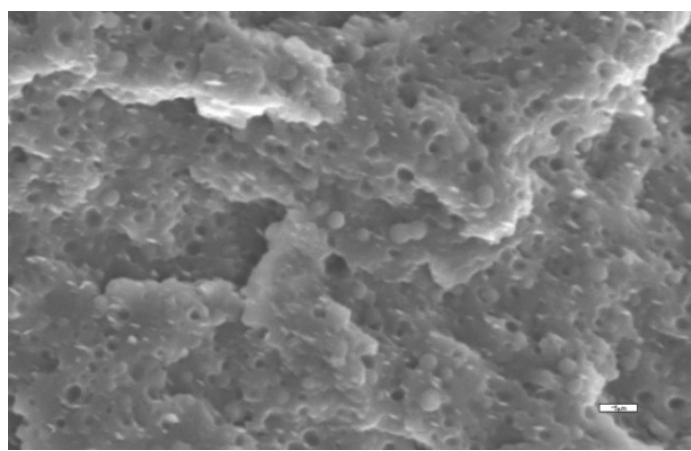

Figure 7: Material PP/B6

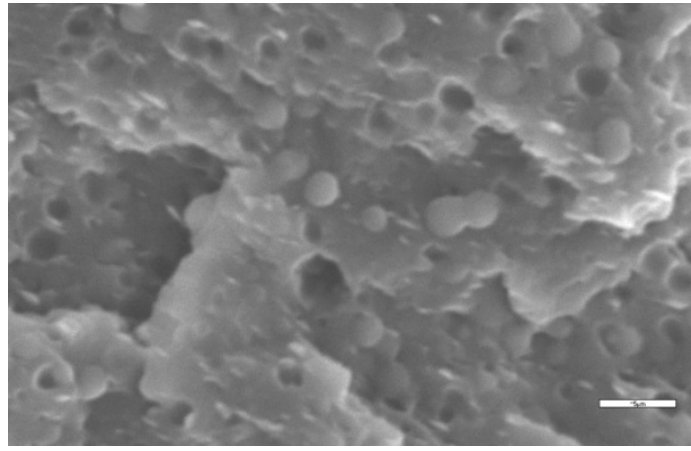

Figure 9: Material PP/B6 


\section{CONCLUSION}

This contribution deals with the study of the influence of montmorillonite in a polypropylene matrix. As it was pointed out in the experimental part of this article, the preparation of polymer nanocomposites is difficult and can lead to the preparation of microcomposites when adhesion forces between the matrix and the filler are not strong enough. In our case, some of the properties were positively influenced, but properties like tensile strength decreased. This decrease was then explained using SEM images, where visible clumps of filler and undigested filler were found. Our next goal is to supply the matrix/filler with compatibilizer to increase the hydrophilicity of polypropylene.

\section{ANKNOWLEDGMENT}

This paper is the result of the implementation of project PIRSES-GA-2010-269177, supported by the international project realized under the scope of the Seventh Frame Programme of European Union (FP7), Marie Curie Actions, PEOPLE, International Research Staff Exchange Scheme (IRSES).

\section{REFERENCES}

[1] Anadão, P.: Nanocomposites - New Trends and Developments, Intech, 2012, ISBN 978-95351-0762-0

[2] Okada, A., et al.: Composite material and process for manufacturing same. Kabushiki Kaisha Toyota Chou Kenkyusho., 1988, US Patent 4739007.

[3] Kawasumi, M., et al.: Process for producing composite material. .Kabushiki Kaisha Toyota Chuo Kenkyusho, 1989, US Patent 4810734

[4] Pavlidou, S., \& Papaspyrides, C. D.: A review on polymer-layered silicate nanocomposite. Progress in Polymer Science ., 33-1119, 2008

[5] Nguyen, Q. T., \& Baird, D. G.: Preparation of polymer-clay nanocomposites and their properties. Advances in Polymer Technology, 25-270, 2006

[6] Patterson, T.: Nanocomposites- our revolutionary breakthrough. . In: 4th World Congress in Nanocomposites San Francisco, USA, 2004

[7] Zhang, Z., Friedrich, K.: Artificial neural networks applied to polymer composites: a review. Composites Science and Technology, Vol. 63, 2029-2044, 2003

[8] Usuki, A.; Kawasumi, M.; Kojima, Y.; Okada, A.; Kurauchi, T. \& Kamigaito, O. J.: Swelling behavior of montmorillonite cation exchanged for $\mathrm{V}$-amino acids by Ecaprolactam. Mater. Res., Vol. 8, No.5, 1174, 1993

[9] Paul, D.R. \& Robeson L.M.: Polymer nanotechnology: Nanocomposites. Polymer, Vol. 49, 3187-3204, 2008 